\title{
Perdas hídricas e desempenho dos reservatórios receptores do PISF na bacia do Rio Paraíba
}

Diante de um cenário recorrente de escassez hídrica no semiárido nordestino, o Projeto de Integração do Rio São Francisco (PISF) foi realizado para mitigar esses problemas. A bacia hidrográfica do Rio Paraíba é beneficiada pelo Eixo Leste do PISF, o qual a partir do município de Monteiro/PB é transportado através do leito do rio Paraíba. Essa forma de transpor as águas acarreta em consideráveis perdas hídricas e financeiras para o sistema. Sendo assim, o objetivo desse trabalho é avaliar as perdas hídricas em trânsito no rio e por evaporação nos quatro reservatórios receptores da vazão exógena do PISF na bacia do rio Paraíba (PB). Para tanto, foram propostos cenários de operação do sistema considerando a forma atual de transporte da vazão do PISF (através do leito do rio Paraíba) e o transporte de parte dessa vazão através de uma adutora até a Estação de Tratamento de Água (ETA) de Gravatá. Estes cenários apresentam restrições do uso da água estabelecido pela Resolução Conjunta ANA/AESA no 87. Utilizou-se, para tanto, um modelo de otimização multiobjetivo baseado em Programação Linear (PL) para a operação do sistema considerando o período hidroclimático de 2012 a 2017, este marcado por forte seca na região. 0 desempenho do sistema foi avaliado por meio de indicadores de desempenho de atendimento as demandas e de eficiência dos reservatórios. Concluiu-se que o cenário considerando a adutora proposta demonstram maior eficiência do uso da água com as menores perdas e que é possível o aumento das demandas em determinados pontos do sistema.

\section{Water losses and performance of receiving reservoirs of the PISF in Paraiba River basin}

\begin{abstract}
According to the water scarcity situation in the semiarid region, the São Francisco River Integration Project (PISF) was undertaken to mitigate these problems. The Paraíba River basin benefits from the PISF East Axis, which from the municipality of Monteiro-PB is transported through the Paraiba river. This way of transposing the waters entails considerable water and financial losses to the system. The objective of this work is to evaluate water losses in transit on the river bed and by evaporation of four reservoirs located along the Paraíba river, when considering the water transposition of the São Francisco river (Project of Integration of São Francisco river - PISF). Two system's operation scenarios were considered: 1- considering the current form of the PISF flow transportation (through the river bed), 2- considering part of the flow being transported by pipelines to the water treatment plant of Gravatá. Considering the above scenarios using water restrictions established by the 87th Joint Resolution of the National Water Agency - ANA and the Paraiba Water Resources Management Executive Agency - AESA. A multiobjective optimization model, based on successive linear programming, was used when considering the period of time from 2012 to 2017, which was marked by severe drought in the region. The system performance was evaluated through the use of indicators related to the meeting water demands and the efficiency of reservoirs. Scenario considering pipeline were more efficient, either regarding to the water demand supply or water losses and that increased demand is possible at certain points in the system.
\end{abstract}

Keywords: Reservoir Operation; Indicator; Optmization.

Topic: Engenharia de Recursos Hídricos

Reviewed anonymously in the process of blind peer.
Received: $12 / 08 / 2019$

Approved: 27/09/2019
Virgínia da Costa Brito (iD

Universidade Federal de Campina Grande, Brasil

http://lattes.cnpq.br/3293234957426500

http://orcid.org/0000-0002-5776-0612

virginia.dcb@gmail.com

Valterlin da Silva Santos (iD

Universidade Federal de Campina Grande, Brasil

http://lattes.cnpq.br/4740303724015282

http://orcid.org/0000-0002-4789-2937

valterlin@yahoo.com.br

Wilson Fadlo Curi (iD)

Universidade Federal de Campina Grande, Brasil

http://lattes.cnpq.br/4941338019932170

http://orcid.org/0000-0002-7024-7127

wfcuri@yahoo.com.br

\author{
Thiago Cabral Nepomuceno (iD \\ Universidade Federal de Campina Grande, Brasil \\ http://lattes.cnpq.br/6513462502498555 \\ http://orcid.org/0000-0002-3452-6647 \\ thiago.nepomucenoesa@gmail.com \\ Francisco de Assis da Costa Neto (iD) \\ Universidade Federal de Campina Grande, Brasil \\ http://lattes.cnpq.br/6054580787671400 \\ http://orcid.org/0000-0001-9681-3919 \\ francisco.costa@ufcg.edu.br
}

Referencing this:

SOBRENOME, N. N.; SOBRENOME, N. N.. Perdas hídricas e desempenho dos reservatórios receptores do PISF na bacia do Rio Paraíba. Revista Ibero Americana de Ciências Ambientais, v.10, n.5, p.114-127, 2019. DOI: http://doi.org/10.6008/CBPC2179$\underline{6858.2019 .005 .0011}$ 


\section{INTRODUÇÃO}

Os conflitos pelo acesso e uso dos recursos hídricos em qualidade e quantidade adequadas vêm sendo intensificados devido aos desafios da crescente demanda e a consequente diminuição da sua disponibilidade, acarretando em problemas ambientais, sociais, econômicos e de políticas públicas. Essa questão é intensificada com as condições naturais do ambiente em que está inserido o Estado da Paraíba, onde maior parte do território está localizado numa região de clima semiárido, caracterizado por chuvas bastante irregulares a nível espaço-temporal, índices pluviométricos baixos e com perdas evaporativas nos reservatórios muito altas quando comparadas a outras regiões do Brasil (VIEIRA, 1996).

O semiárido paraibano sofre frequentemente com secas prolongadas que dificulta o atendimento das demandas hídricas tanto de abastecimento humano como para a irrigação de áreas agrícolas, a prática da piscicultura extensiva e/ou intensiva, entre outros usos. Uma das soluções apresentadas para minimizar esse problema foi à construção de reservatórios para armazenamento da água no período chuvoso objetivando seu uso posterior, à custa de elevadas perdas de água por evaporação.

Entretanto, Rêgo et al. (2000) relata que durante a ocorrência da seca de 1997-1999, diante da ameaça de colapso total do abastecimento urbano da cidade de Campina Grande (2a maior cidade do Estado da Paraíba e do interior do Nordeste), representado pelo baixo nível a que ficou reduzido o volume d'água acumulado no reservatório Epitácio Pessoa (2ำ maior reservatório do Estado da Paraíba), foi necessário a implantação de um regime de racionamento da distribuição de água, que teve início no segundo semestre de 1998 e prolongou-se até os primeiros meses do ano 2000.

Ao racionamento seguiu-se a suspensão, por medida judicial, da irrigação que vinha sendo praticada, sem nenhum controle técnico, nas margens do açude e o fechamento da comporta de descarga de fundo para a perenização do rio Paraíba. Durante a seca que se iniciou no ano de 2012, diversas cidades paraibanas sofreram com longos racionamentos no sistema de distribuição de água e nas atividades agropastoril devido aos baixos volumes de água armazenados nos reservatórios da região.

No caso reservatório Epitácio Pessoa, em março de 2013 o Ministério Público e o DNOCS (Departamento Nacional de Obras Contra a Seca) decretaram a suspensão da irrigação em torno do açude, devido à perda de cerca 128 milhões de metros cúbicos de água no período de fevereiro de 2012 a fevereiro de 2013. Em dezembro de 2014 a CAGEPA (Companhia de Águas e Esgoto do Estado da Paraíba) iniciou um racionamento de água de 02 (dois) dias na cidade de Campina Grande e mais 18 cidades da região. Em outubro de 2015 , quando o reservatório estava com $14 \%$ de sua capacidade de armazenamento, houve a ampliação do racionamento para mais 05 (cinco) dias.

Entretanto, como não houve precipitações suficientes para elevar o nível d'água do reservatório, em dezembro de 2015 , quando o reservatório estava com menos de $10 \%$ de sua capacidade, a CAGEPA instalou um sistema de captação flutuante no reservatório de modo a garantir o abastecimento dos centros urbanos. Contanto, em julho de 2016 o nível de água do reservatório atingiu o volume morto, diminuindo até atingir a marca histórica de apenas $2,9 \%$ da sua capacidade de armazenamento (11,97 milhões de metros cúbicos) 
em abril de 2018.

Para minimizar as consequências das secas na região, foi idealizado o Projeto de Integração do Rio São Francisco (PISF) com Bacias Hidrográficas do Nordeste Setentrional através de dois eixos - Eixo Norte e Eixo Leste. O objetivo do projeto é assegurar a oferta de água, com garantia de atendimento para a população; fornecer água de forma complementar para açudes existentes na região, viabilizando uma melhor gestão da água e; reduzir as diferenças regionais causadas pela oferta desigual da água entre bacias e populações (RIMA, 2004).

No Estado da Paraíba será beneficiada a bacia do rio Piranhas-Açu - através do Eixo Norte - e a bacia do rio Paraíba - através do Eixo Leste. Esta última é responsável pelo abastecimento da cidade de Campina Grande. Em março de 2018 as águas do PISF chegaram à cidade de Monteiro - PB (divisa com o Estado de Pernambuco), sendo que após 41 dias de percurso no leito do rio Paraíba elas chegaram ao reservatório Epitácio Pessoa, aumentando o nível de água gradativamente. Ao ponto que em agosto de 2016 o reservatório atingiu novamente o seu volume morto, de modo que a CAGEPA suspendeu totalmente o racionamento de água para Campina Grande e mais 18 cidades abastecidas pelo reservatório.

De acordo com Farias et al. (2017), a proposta inicial do PISF é de transportar toda vazão exógena através do leito do rio (como está sendo atualmente), mas isso aumenta significativamente as perdas em trânsito por infiltração, evaporação, desvios, etc., e como essa água perdida tem um custo fixo relativamente alto, uma solução viável para reduzir as perdas seria transportar parte dessa vazão por meio de uma adutora até os pontos de consumo.

Diante disto, o presente trabalho traz um estudo sobre uma possível forma de transportar parte da vazão exógena advinda do PISF na bacia do rio Paraíba objetivando o melhor aproveitamento do uso dos recursos hídrico em questão, avaliando as perdas hídricas decorrentes do percurso da água no leito do rio e por evaporação nos reservatórios.

Para tanto, criou-se cenários que se diferenciam pela forma de transportar a vazão do projeto e pelo uso das águas. Estes cenários, foram analisados por meio de um modelo de otimização multi-objetivo, baseado em Programação Linear (PL), desenvolvido por Santos et al. (2011), para um horizonte de tempo de 6 anos (2012-2017) período este caracterizado por uma das piores secas sofridas pela região de estudo.

\section{MATERIAIS E MÉTODOS}

\section{Área de estudo}

A Bacia hidrográfica do Rio Paraíba (Figura 1) está totalmente inserida no Estado da Paraíba, apresenta uma área de $20.071,83 \mathrm{~km}^{2}$, abrangendo $38 \%$ do seu território e abrigando 1.828 .178 habitantes que correspondem a $52 \%$ da sua população total. Ela é composta pela sub-bacia do Rio Taperoá e Regiões do Alto, do Médio e do Baixo Curso do rio Paraíba. Nela estão inseridas as cidades de João Pessoa, capital do Estado e de Campina Grande.

Neste estudo foram considerados os quatros reservatórios da bacia receptores da vazão do PISF 
(Poções, Camalaú, Epitácio Pessoa, também conhecido como Boqueirão e Argemiro Figueiredo também conhecido como Acauã) como também os reservatórios a montante ao reservatório Boqueirão com uma capacidade maior que 10 milhões de metros cúbicos (Sumé, Santo Antônio, Cordeiro, Serra Branca II, Soledade, Mucutu, Taperoá II), pois os mesmos influenciam na vazão afluente ao reservatório. A Figura 2 apresenta o layout do sistema com os reservatórios considerados no estudo com suas respectivas demandas.



Figura 1: Mapa da Bacia Hidrográfica do Rio Paraíba.

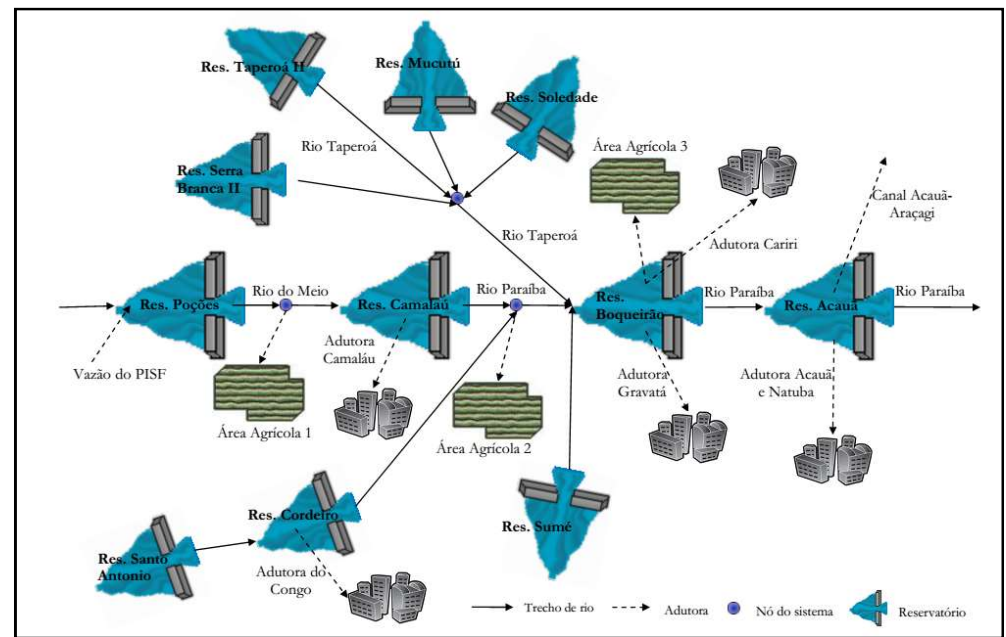

Figura 2: Layout dos reservatórios estudados com suas respectivas demandas.

As áreas agrícolas propostas estão de acordo com estudos do Plano Diretor de Recursos Hídricos da Bacia do rio Paraíba (TC/BR RIVERSIDE TECHONLOGY, 2001). As adutoras consideradas estão em operação e/ou em fase de expansão.

\section{Delineamento dos Cenários}

\section{Cenário C1}

O Cenário C1 representa a situação real do sistema no qual a água do PISF chega ao reservatório Poções seguindo pelo leito do rio até os reservatórios de Camalaú, Boqueirão e Acauã. Este cenário considera a Resolução Conjunta ANA/AESA-PB no 87 , de 05 de novembro de 2018, a qual estabelece as condições de uso de recursos hídricos superficiais e subterrâneos para o Sistema Hídrico Rio Paraíba - Boqueirão, no Estado da Paraíba, limitando os usos da água da transposição, conforme seu Art. $4^{\circ}$, Incisos I e II: I - a área de cultivo no entorno do Açude Epitácio Pessoa (Boqueirão) e ao longo do rio Paraíba fica limitada a 250,0 ha (duzentos e cinquenta hectares), para cada trecho; II - a vazão autorizada a cada usuário de recursos hídricos será 
limitada à necessária para o cultivo em área máxima de 0,50 ha ou volume máximo diário igual a 25.920 L.

\section{Cenário C2}

O Cenário C2 considera que uma parcela das águas do PISF será transportada por meio de uma adutora até a ETA Gravatá, localizada no município de Queimadas/PB. A vazão transportada por essa adutora será a demanda hídrica requerida pela ETA Gravatá para o atendimento do abastecimento urbano de Campina Grande e mais 9 cidades da região. Este cenário também considera a Resolução Conjunta ANA/AESA-PB no 87, de 05 de novembro de 2018 da mesma forma do Cenário C1 para o uso de recursos hídricos superficiais da região.

\section{Dados do Sistema}

\section{Demandas hidricas}

Para cálculo da demanda de abastecimento urbano, foi feito, inicialmente, um estudo do crescimento populacional dos municípios de cada adutora do sistema para um horizonte de 6 (seis) anos. Foram utilizados os dados dos últimos censos disponibilizados pelo IBGE (2018). Foi utilizado o software LAB Fit (SILVA et al., 2004) para tratamento de dados experimentais. Os dados de consumo per capita de cada município e dados das perdas no sistema de distribuição da água foram coletados no site do SNIS (2018) para o ano de 2012, ano no qual não houve racionamento de água no sistema. A Tabela 1 apresenta os valores utilizados no estudo.

Tabela 1: Vazões requeridas $\left(\mathrm{m}^{3} / \mathrm{s}\right)$ para as adutoras no período analisado.

\begin{tabular}{|l|l|l|l|l|l|l|}
\hline ADUTORA & Ano 1 & Ano 2 & Ano 3 & Ano 4 & Ano 5 & Ano 6 \\
\hline Camalaú & 0,01 & 0,01 & 0,01 & 0,01 & 0,01 & 0,01 \\
\hline Congo & 0,13 & 0,13 & 0,14 & 0,14 & 0,14 & 0,14 \\
\hline Cariri & 0,09 & 0,09 & 0,09 & 0,09 & 0,09 & 0,09 \\
\hline Gravatá & 1,09 & 1,10 & 1,11 & 1,12 & 1,13 & 1,13 \\
\hline Acauã e Natuba & 0,27 & 0,27 & 0,27 & 0,27 & 0,27 & 0,28 \\
\hline
\end{tabular}

Para a avaliação das demandas hídricas das áreas agrícolas nos cenários C1 e C2 foi considerada a Resolução Conjunta ANA/AESA-PB no 87, de 5 de novembro de 2018, a qual permite a irrigação apenas de culturas temporárias. Desse modo, para a área agrícola 1 entre os reservatórios de Poções e de Camalaú foi estimada uma área de 50 ha, cuja demanda será de 30,0 L/s para todos os meses do ano. Para a área agrícola 2 entre os reservatórios de Camalaú e de Boqueirão foi estimada uma área de 200 ha, cuja demanda será de 120,0 L/s para todos os meses do ano. Para a área agrícola 3 foi considerada uma área de 250 ha, cuja demanda será de 150,0 L/s para todos os meses do ano.

\section{Precipitação}

Para o cálculo da precipitação direta nos reservatórios foram utilizados valores dos postos pluviométricos disposto no Quadro 1. Os valores utilizados são correspondentes aos dados mensais de precipitação de 2012 a 2017 (anos considerados como uma das maiores secas da região) obtidos da AESA. 
Quadro 1: Postos pluviométricos utilizados

\begin{tabular}{|l|l|}
\hline Reservatórios & Postos pluviométricos utilizados \\
\hline Acauã & Itatuba \\
\hline Epitácio Pessoa & Boqueirão \\
\hline Camalaú & Camalaú \\
\hline Poções & Monteiro \\
\hline Soledade & Soledade \\
\hline Mucutu & Assunção \\
\hline Taperoá II & Taperoá \\
\hline Serra branca II & Serra Branca \\
\hline Sumé & Sumé \\
\hline Santo Antônio & São Sebastião do Umbuzeiro \\
\hline Cordeiro & Congo \\
\hline
\end{tabular}

\section{Evaporação}

Para o cálculo da evaporação mensal dos reservatórios utilizou-se dados da taxa de evaporação de tanques evaporimétricos tipo Classe A obtidos de três postos climatológicos disposto no Quadro 2. Os valores mensais do coeficiente do tanque foram estimados por Oliveira et al. (2005) para a região do cariri paraibano.

Quadro 2: Postos climatológicos utilizados para o cálculo de evaporação média mensal dos reservatórios.

\begin{tabular}{|l|l|}
\hline Posto Climatológico & Reservatório \\
\hline Monteiro & Poções, Camalaú, Cordeiro, Santo Antônio e Sumé \\
\hline São João do Cariri & Taperoá II, Mucutu, Serra Branca II, Soledade e Boqueirão \\
\hline Campina Grande & Acauã \\
\hline
\end{tabular}

\section{Vazões Afluente}

Os dados de vazões afluentes aos reservatórios e nós do sistema foram gerados pelo o modelo hidrológico chuva x vazão SMAP-M (LOPES et al., 1981). O modelo foi calibrado e validado utilizando-se séries de vazões do posto fluviométrico de Poço de Pedras (DINIZ, 2008), onde foram geradas as séries de deflúvios médios mensais de janeiro de 2012 a dezembro de 2017 a partir de dados de precipitação totais mensais.

\section{Dados dos reservatórios utilizados}

Os dados das curvas cota-área-volume, das descargas de fundo e vertedouros foram obtidos do Cadastro de Açude do Plano Diretor de Recursos Hídricos da Bacia do rio Paraíba (TC/BR RIVERSIDE TECHONLOGY, 2001). O volume morto, a capacidade de armazenamento (volume máximo) e os dados dos volumes iniciais para os onze reservatórios foram disponibilizados pela AESA.

\section{Modelo de Simulação}

Com o intuito de verificar as vazões de fluentes (vertidas) dos reservatórios Santo Antônio, Cordeiro, Sumé, Soledade, Mucutu, Taperoá II e Serra Branca II, que afluem para o reservatório Boqueirão, foi realizado a simulação da operação de cada reservatório separadamente utilizando o seguinte modelo:

$$
\begin{gathered}
\text { Equação 1: } V r_{t+1}=V r_{t}+Q a_{t}-R_{t}+P r_{t}-E v r_{t}-Q v_{t} \\
\text { Equação 2: } V r_{\min } \leq V r_{t} \leq V r_{\max } \\
\text { Equação 3:0 } \leq R_{t} \leq D_{t} \\
\text { Equação 4: } 0 \leq Q v_{t} \leq Q v_{\max }
\end{gathered}
$$


Sendo: $V r_{t}$ o volume de água do reservatório no início do mês $t$; $V r_{t+1}$ o volume de água do reservatório no final do mês $\mathrm{t}+1$; $\mathrm{Q} \mathrm{at}_{\mathrm{t}}$ a vazão afluente ao reservatório durante o mês $\mathrm{t} ; \mathrm{R}_{\mathrm{t}} \mathrm{o}$ volume de água retirado de água do reservatório para satisfazer determinada demanda $D_{t}$ durante o mês $t$; $P_{t}$ a precipitação direta sobre o espelho d'água do reservatório durante mês t; Evrt o volume de água evaporado no reservatório durante o mês $t, Q_{t}$ o volume de água vertido do reservatório durante o mês $\mathrm{t}$; $\mathrm{Vr}_{\min }$ o volume mínimo de água (ou morto) do reservatório; $\mathrm{Vr}_{\max }$ a capacidade máxima de água do reservatório; Q vmax o volume máximo de água que pode passar pelo vertedouro.

As retiradas de água do reservatório foram efetuadas utilizando a chamada Política de Operação Linear Padrão (SLOP, da abreviação em inglês). A SLOP especifica a vazão de retirada do reservatório em função da água disponível (volume total e afluências previstas). Quando a disponibilidade hídrica é menor do que as demandas, todo o armazenamento é liberado para satisfazer as demandas, do contrário o excesso de água é armazenado no reservatório até que sua capacidade de acumulação seja atingida e o vertimento ocorra (LOUCKS et al., 1981).

\section{Modelo de Otimização}

Para avaliar o uso da água nos quatros reservatórios receptores da vazão do PISF e as perdas hídricas no sistema estudado foi utilizado o modelo de otimização multiobjetivo desenvolvido por Santos et al. (2011). O modelo é baseado em programação linear, utilizando o Toolbox Optimization do software MATLAB 6.5 com o Método do Ponto Interior para a busca da solução ótima. Para tanto, linearizações apropriadas das não linearidades intrínsecas aos processos de cada um de seus componentes tiveram que ser pesquisadas e implementadas através do uso combinado do Artifício de Linearização por Segmentos e da Programação Linear Sequencial.

O modelo se destina a otimizar os múltiplos usos de um sistema de reservatórios, com a implantação ou melhoramento da operação das irrigadas. O mesmo trabalha com variáveis relacionadas aos elementos naturais, tais como: hidroclimáticos e hidroagrícolas, como também outras variáveis (demandas hídricas, características físicas dos componentes, etc.) identificadas no estudo do sistema hídrico. Para estes elementos, são definidas as informações necessárias ao modelo para a entrada de dados, envolvendo: reservatórios, demandas, calhas dos rios e perímetros irrigados.

A operação do reservatório e dos nós é fundamentada na equação do balanço hídrico destes elementos naturais, mesmo quando se faz uso de demandas fixas e variáveis. A demanda hídrica de um perímetro irrigado é determinada com base na necessidade suplementar líquida de irrigação, estabelecida através do balanço hídrico, no solo, para as culturas selecionadas, estando a área a ser plantada limitada pelos demais usos do reservatório. O modelo também leva em consideração os diferentes tipos de sistemas de irrigação e suas necessidades de altura manométrica, as áreas a serem irrigadas para cada tipo de cultura, os custos de água e de produção, os aspectos econômicos e a combinação ou variação nas fontes de bombeamento e a quantidade de água captada.

Como se trata de uma otimização multiobjetivo, utilizou-se o Método das Ponderações, na qual cada função objetivo é normalizada sendo atribuídos pesos para definir as prioridades de atendimento. Neste trabalho, o modelo de otimização tem como objetivo principal prover um estudo da operação integrada do sistema de reservatórios e do atendimento às demandas do sistema com foco na alocação ótima dos recursos 
hídricos, entre os múltiplos usos via uma análise multi-objetivo.

\section{Indicadores de desempenho e eficiência}

De acordo com Farias et al. (2017) os estudos de recursos hídricos usam uma grande quantidade de dados, o que tornam as propostas de gerenciamento uma tarefa muito difícil. Para isso é necessário criar parâmetros de avaliação que retenham apenas os dados essenciais, que são chamados de indicadores de desempenho de atendimento das demandas e os indicadores de eficiência associado aos reservatórios, os quais são baseados em equação de balanço hídrico.

Os indicadores de desempenho de atendimento das demandas utilizados nesse trabalho foram propostos Hashimoto et al. (1982), sendo eles: Confiabilidade (Conf) - indica a probabilidade de a demanda ser atendida sem falha; Resiliência (Res) - indica a probabilidade de uma demanda recuperar-se de uma falha, caso ela ocorra. Em alguns casos, um sistema que apresenta muitas falhas, mas que se recupera rapidamente é mais preferível a aquele que apresente poucas falhas e se recupere lentamente (FARIAS et al., 2017); Vulnerabilidade (Vul) - indica a magnitude da falha que a demanda está sujeita, caso ela tenha ocorrido.

Foi também calculada a Vulnerabilidade máxima (Vulmax) que indica a magnitude máxima da falha a que a demanda está sujeita, caso ela tenha ocorrido. Os indicadores de eficiência associados aos reservatórios foram baseados no trabalho de Farias et al. (2017): $\eta V R$ - relação entre a variabilidade volumétrica do reservatório e o volume afluente total ao reservatório (vazão afluente mais a precipitação direta no espelho d'água). Indica a variabilidade interanual do volume do reservatório. Valores negativos indicam depleção no nível do reservatório (anos de seca) e positivos indicam acúmulo/ganho de água no reservatório; $\eta \mathrm{Ev}$ - relação entre o volume evaporado e o volume afluente total do reservatório. Este índice tem como características: estabelecer a eficiência de armazenamento de água; pode indicar que o reservatório apresenta baixa profundidade e grande área de espelho d'água; pode ser usado para determinar o tempo em que a água deve ser usada para reduzir as perdas por evaporação; $\eta \mathrm{P}$ - relação entre a precipitação direta sobre a bacia hidráulica do reservatório (espelho d'água) e o seu volume total afluente. Este índice indica a porcentagem de precipitação direta na bacia hidráulica. Pode indicar que o reservatório possui baixa profundidade e grande área de espelho d'água. Altas taxas indicam que a bacia de contribuição é pequena; $\eta Q v$ - relação entre o volume vertido e o volume afluente total do reservatório. Este índice tem como características: estabelecer a eficiência de armazenamento de água ou a capacidade relativa do reservatório. Indica quanto do volume total afluente do reservatório é perdida por vertimento; $\eta Q u$ - relação entre o volume de água utilizada (descarga de fundo, adutoras, etc.) e o volume total afluente do reservatório. Este índice tem como característica estabelecer a quantidade de água utilizada em relação ao volume total afluente do reservatório. Altas taxas indicam que há poucas perdas no sistema.

Os indicadores de eficiência associados ao sistema utilizados foram baseados no trabalho de Vieira (1996) adaptado por Farias et al. (2017), são eles: Indicador de ativação da potencialidade (IAP) - relação entre disponibilidade e potencialidade. Indica a porcentagem de água utilizada em relação a toda a água disponível na bacia. Bacias hidrográficas com IAP inferior a 0,6 apresentam possibilidades de aumentar a 
disponibilidade em seu espaço geográfico (VIEIRA, 1996); Indicador de utilização da disponibilidade (IUD) relação entre demanda e disponibilidade. Indica o percentual de água disponível destinado a atender às demandas. Valores acima da unidade são preocupantes ao atendimento das demandas, pois em anos de baixa pluviosidade haverá conflitos pelo uso da água (VIEIRA, 1996); Indicadores de utilização da potencialidade (IUP) - razão entre demanda e potencialidade, indica a quantidade de água (vazão total) utilizada para atendimento das demandas.

A potencialidade é obtida pela soma dos influxos mais a precipitação direta nos reservatórios. A disponibilidade é igual à potencialidade menos as perdas (volume de água perdido em trânsito no leito do rio, evaporação nos reservatórios e volumes vertidos a jusante do sistema). E as demandas são os usos consuntivos (abastecimento humano, irrigação, entre outros) (FARIAS et al., 2017).

\section{Critérios operacionais}

Os cenários observaram os seguintes critérios operacionais: O período de estudo corresponde a 6 (seis) anos, iniciando o processo de otimização no mês de janeiro; O volume de água inicial dos reservatórios foi considerado igual ao do dia 01 de janeiro de 2012; O volume de água do reservatório, ao final do período de estudo de otimização, deve ser maior ou igual ao volume inicial, garantindo a sustentabilidade hídrica das atividades econômicas; O volume meta dos reservatórios, em todos os meses, foi considerado igual à capacidade dos mesmos; As capacidades das tomadas d'água destinada ao abastecimento humano foram consideradas iguais as suas respectivas demandas; As perdas por evaporação e a infiltração em cada calha do rio foram consideradas da ordem de 5\% entre os reservatórios Poções e Camalaú; de 20\% entre Camalaú e Boqueirão e de $20 \%$ entre Boqueirão e Acauã; O Canal Acauã-Araçagi tem uma capacidade máxima de 10 $\mathrm{m}^{3} / \mathrm{s}$, sendo esse valor considerado como sua demanda; As prioridades de atendimento foram: 1a atendimento da demanda de abastecimento urbano das adutoras; $2^{\circ}$ atendimento da demanda das áreas agrícolas; 3 o atendimento da demanda do canal Acauã-Araçagi; 4o atendimento ao volume meta dos reservatórios.

\section{RESULTADOS E DISCUSSÃO}

\section{Simulação}

Com base na metodologia e nos dados apresentados houve vertimento apenas nos reservatórios de Mucutu, Taperoá Il e Sumé para o período analisado (2012-2017). A Tabela 2 apresenta os volumes vertidos por ano para esses reservatórios. Tais volumes foram adicionados a vazão afluente do reservatório Boqueirão para análise no modelo de otimização.

Tabela 2: Volumes vertidos $\left(\mathrm{m}^{3} / \mathrm{s}\right)$ dos reservatórios a montante do reservatório Boqueirão.

\begin{tabular}{|l|l|l|l|l|l|l|}
\hline & 2012 & 2013 & 2014 & 2015 & 2016 & 2017 \\
\hline Mucutu & 0,0 & 0,0 & 0,0 & 0,0 & 1,6 & 0,0 \\
\hline Taperoá II & 0,0 & 0,0 & 6,7 & 2,8 & 8,8 & 2,4 \\
\hline Sumé & 0,0 & 0,0 & 19,9 & 0,0 & 5,8 & 8,0 \\
\hline
\end{tabular}




\section{Otimização}

Tem-se que as demandas estabelecidas para as adutoras de abastecimento urbano e para as áreas agrícolas foram atendidas sem apresentar falhas nos dois cenários propostos. A única exceção ocorreu no atendimento da demanda do canal Acauã-Araçagi, como mostra a Figura 3, onde em nenhum momento foi possível atender a sua capacidade máxima.

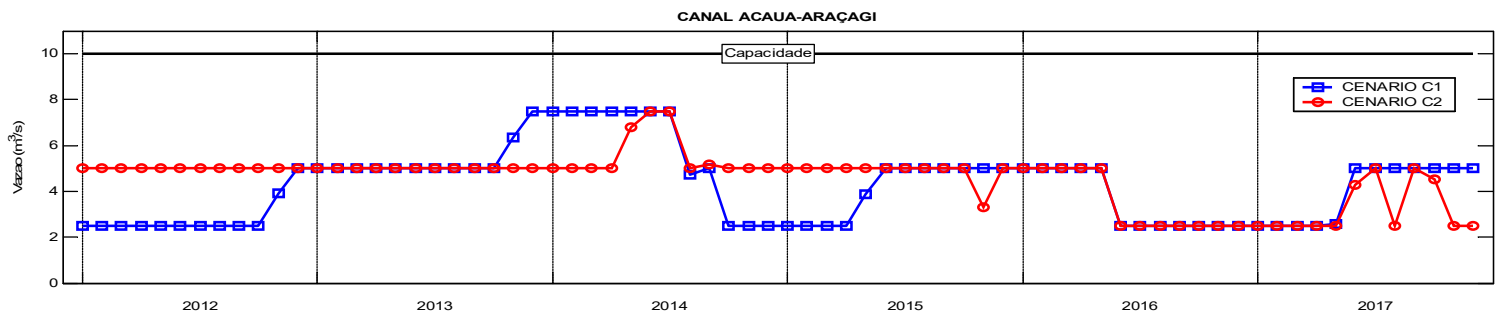

Figura 3: Atendimento do canal Acauã-Araçagi para os cenários.

A Tabela 3 apresenta indicadores de desempenho de atendimento da demanda do canal AcauãAraçagi para os cenários propostos. A confiabilidade e a resiliência foram iguais a zero porque não foi possível suprir, para o período analisado, a demanda do canal Acauã-Araçagi (capacidade máxima). A vulnerabilidade foi de aproximadamente $60 \%$ do valor da demanda, podendo chegar a $75 \%$ (vulnerabilidade máxima), ou seja, em média, o sistema será capaz de fornecer ao canal um fluxo de $4 \mathrm{~m}^{3} / \mathrm{s}$ e algumas vezes liberar apenas $2,5 \mathrm{~m}^{3} / \mathrm{s}$. A Figura 4 apresenta as vazões médias vertidas e liberadas por descarga de fundo dos reservatórios para o período analisado e cenários propostos.

Tabela 3: Indicadores de desempenho de atendimento da demanda do canal Acauã-Araçagi.

\begin{tabular}{|l|l|l|l|l|}
\hline CANAL ACAUÃ-ARAÇAGI & CONF & RES & VUL & VULMAX \\
\hline CENÁRIO C1 & 0 & 0 & 0,57 & 0,75 \\
\hline CENÁRIO C2 & 0 & 0 & 0,55 & 0,75 \\
\hline
\end{tabular}

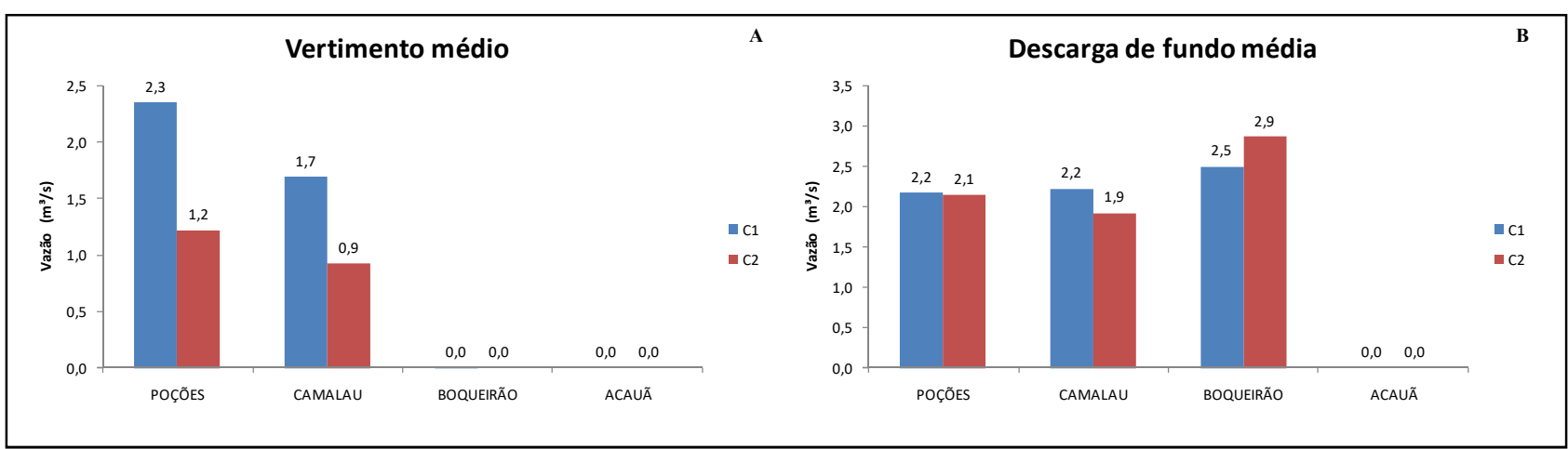

Figura 4: Vertimento médio anual $\left(\mathrm{m}^{3} / \mathrm{s}\right)$ e vazão média anual liberada por descarga de fundo $\left(\mathrm{m}^{3} / \mathrm{s}\right)$ liberada dos reservatórios nos cenários propostos.

Observa-se que o vertimento (Figura 4A) ocorreu apenas nos reservatórios de Poções e Camalaú devido ao alto volume afluente proveniente, principalmente, do PISF e por suas capacidades de armazenamento serem relativamente baixas, pois esses reservatórios foram projetados para acumular as precipitações ocorridas na região. As maiores vazões vertidas ocorreram no cenário C1 (cenário com maior quantidade de água no sistema, pois a adutora até a ETA Gravatá não é considerada). Nos reservatórios de 
Boqueirão e Acauã não ocorreram vertimentos em nenhum cenário ao longo do período de estudo, devido às suas capacidades de armazenamento e ao grande valor de suas demandas.

Tem-se que as maiores vazões liberadas pela descarga de fundo dos reservatórios Poções e Camalaú (Figura 4B) ocorreram no cenário C1. No reservatório de Boqueirão, as maiores vazões liberadas por descarga de fundo ocorreram no cenário C2 (cenário considerando uma adutora até a ETA Gravatá diminuindo assim as demandas do reservatório Boqueirão) para auxiliar no atendimento das demandas do reservatório Acauã.

O reservatório Acauã não foi capaz de manter uma vazão no rio Paraíba a sua jusante. Este é um fato preocupante devido ao atendimento de outras demandas que podem surgir à jusante do reservatório sendo necessário o estabelecimento de vazões mínimas nos trechos dos rios para o sistema em estudo. A Figura 5 mostra os volumes mensais de água dos reservatórios para os cenários propostos.



Figura 5: Volume de água dos reservatórios para os cenários propostos.

Observa-se que os volumes dos reservatórios de Poções e Camalaú apresentam, na maioria dos casos, em seus níveis máximos devido ao fluxo de água do PISF e baixa capacidade de armazenamento destes. No mês de julho do ano de 2014, os volumes de água dos reservatórios de Boqueirão e Acauã atingiram suas capacidades de armazenamento, permanecendo sempre com um volume superior a $60 \%$ devido à necessidade de atendimento da sustentabilidade hídrica (volume de água do reservatório no final do período de estudo deve ser maior ou igual ao volume inicial).

Tem-se que o volume de água do reservatório Boqueirão é menor no cenário $\mathrm{C} 2$ do que no cenário C1, por causa da menor vazão exógena no sistema proveniente do PISF nesse cenário (parte da vazão do PISF 
foi direcionada diretamente para a ETA Gravatá) e da maior transferência de água para o reservatório Acauã para o atendimento de suas demandas. Fato não ocorrido no reservatório Acauã onde em vários meses o volume de água no cenário C2 foi superior ao volume de água no cenário C1. A Figura 6 apresenta os indicadores de eficiência associados aos reservatórios para os cenários propostos.



Figura 6: Indicadores de eficiência associados aos reservatórios.

Grande parte do volume total afluente dos reservatórios (vazão afluente mais precipitação direta) foi usada para o atendimento de suas demandas ( $\eta \mathrm{Qu})$, principalmente o reservatório Acauã (Figura 6D) no qual cerca de $90 \%$ do volume total afluente foi para tal propósito. A única exceção ocorreu no reservatório Poções no Cenário C1 (Figura 6A), no qual o percentual do volume vertido foi maior que o volume para o atendimento de suas demandas. No reservatório Boqueirão ocorreu uma redução, no cenário $\mathrm{C} 2$, do percentual do volume total afluente destinado ao atendimento de suas demandas (Figura 6C) devido a diminuição de suas demandas nesse cenário. Observa-se, também, uma redução de cerca de $10 \%$ no percentual do volume vertido dos reservatórios Poções e Camalaú no cenário C2.

As perdas por evaporação representaram cerca de $10 \%$ do volume total afluente dos reservatórios de Poções, Camalaú e Acauã. No reservatório Boqueirão, este índice é próximo de $40 \%$ do volume total afluente ao reservatório, por ser a maior bacia hidráulica. O cenário C2 apresentou o maior percentual do volume evaporado em relação ao volume total afluente nos reservatórios de Poções, Camalaú e Boqueirão, fato não ocorrido no reservatório Acauã. A Figura 7 apresenta os índices de eficiência associados ao sistema estudado.

O indicador IAP menor que 0,6, nos cenários analisados, indica que o sistema apresenta possibilidade de aumentar sua disponibilidade com a diminuição das perdas de água (evaporação nos reservatórios e perdas nos leitos dos rios). 0 indicador IUD apresenta valores acima de $95 \%$. Esse fato se deve à grande demanda do canal Acauã-Araçagi, que gera uma grande pressão em todo o sistema, mesmo em cenários em que a demanda de água do sistema é menor (cenário $\mathrm{C2}$ ). O indicador IUP, que relaciona a demanda de água e a entrada potencial no sistema, mostra que as demandas do sistema podem aumentar. Portanto, estudos devem ser realizados para analisar as crescentes demandas do sistema para evitar falhas e conflitos futuros.

A Figura 8 apresenta as perdas hídricas anuais para os cenários propostos. Percebe-se que as menores perdas hídricas ocorrem no cenário $\mathrm{C2}$, que propõe o transporte de parte da vazão do PISF por meio 
de uma adutora até a ETA Gravatá, quando comparado ao cenário que apresenta a atual forma de transposição das águas do PISF (cenário C1). Isso porque parte da vazão transportada pela adutora não sofre perdas ao longo do rio. Entretanto, tem-se também uma redução no volume de água evaporado dos reservatórios do cenário $\mathrm{C} 2$ para o cenário $\mathrm{C} 1$, o que demonstra que a implementação da adutora até a ETA Gravatá reduz consideravelmente as perdas hídricas do sistema.

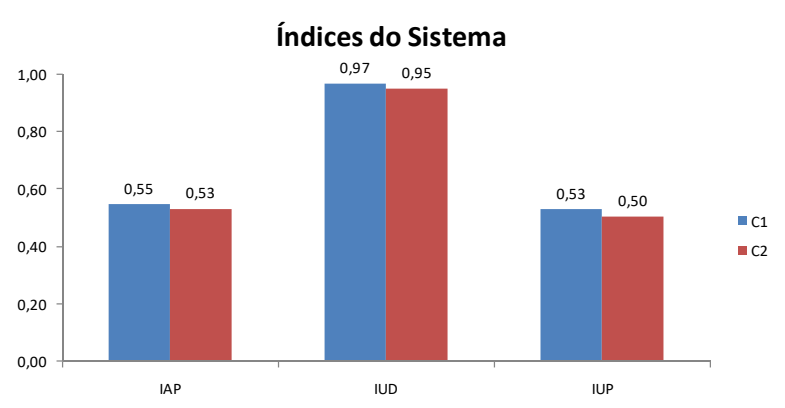

Figura 7: Índices de eficiência no Sistema.

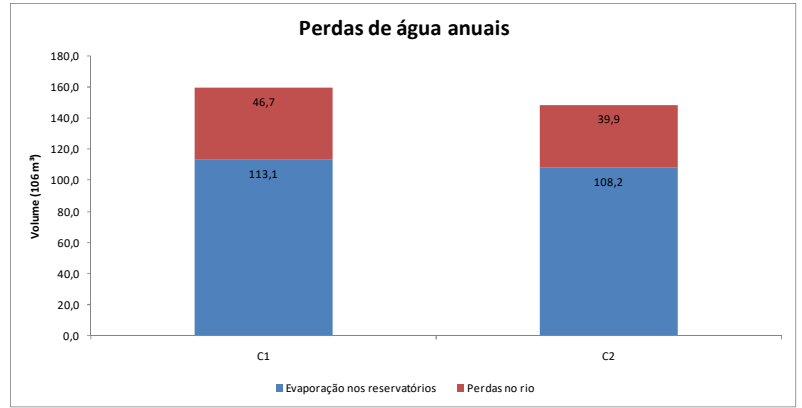

Figura 8: Perdas hídricas anuais para os cenários propostos.

A economia anual de água foi de cerca de 12 milhões de $\mathrm{m}^{3}$ com a implementação da adutora no cenário C2. Este valor corresponde aproximadamente, por um ano, à demanda de água agrícola estabelecida na Resolução Conjunta ANA/AESA n 87 ou a quatro meses da demanda hídrica destinada a ETA Gravatá.

\section{CONCLUSÕES}

Com base na metodologia e nos resultados apresentados se conclui que: A implementação de uma adutora para transportar parte da vazão do PISF até a ETA Gravatá reduzirá bastante as perdas hídricas no sistema; A limitação estabelecida na Resolução ANA/AESA no 87 diminui a eficiência do uso das águas do sistema. De modo que se pode aumentar a área irrigada desde que haja um planejamento adequado; A vazão máxima do canal de integração Acauã-Araçagi sobrecarrega bastante o sistema, principalmente o reservatório de Acauã, sendo recomendado estudos para o estabelecimento de uma vazão firme de modo que não haja alguma demanda reprimida no sistema e não gerando conflitos pelo uso da água na bacia; As águas dos reservatórios Poções e Camalaú podem ser mais bem aproveitadas principalmente para usos não consuntivos (prática da piscicultura e/ou carcinicultura) desde que sejam realizados estudos de viabilidade, para evitar ocorrência de problemas futuros.

AGRADECIMENTOS: ao CNPq por financiar a pesquisa por meio da bolsa concedida.

\section{REFERÊNCIAS}

ANA. Agência Nacional das Águas. Resolução conjunta ANA/AESA-PB n.87: Estabelece as condições de uso de recursos hídricos superficiais e subterrâneos para o Sistema Hídrico Rio Paraíba: Boqueirão, no Estado da Paraíba, durante o período de pré-operação do Projeto de Integração do Rio São Francisco com as Bacias Hidrográficas do Nordeste Setentrional - PISF. João Pessoa: ANA, 2018.
DINIZ, L. S.. Regionalização de parâmetros de modelos chuva-vazão usando redes neurais. Tese (Doutorado em Engenharia de Recursos Hídricos e Saneamento Ambiental) Universidade Federal do Rio Grande do Sul, Porto Alegre, 2008.

FARIAS, E. E. V.; CURI, E. F.; DINIZ, L. S.. São Francisco river Integration Project, Eastern Axis: losses analysis and 
performance indicators. Revista Brasileira de Recursos

Hídricos, v.22, n.47, 2017. DOI:

http://dx.doi.org/10.1590/2318-0331.0217170006

HASHIMOTO, T.; STEDINGER, J. R.; LOUCKS, D. P.. Reliability, resiliency, and vulnerability criteria for water resource system performance evaluation. Water Resources Research, v.18, n.1, p.14-20, 1982

IBGE. Instituto Brasileiro de Geografia e Estatística. Dados Históricos dos Censos. Rio de Janeiro: IBGE, 2018.

LOUCKS, D. P.; STEDINGER, J. R.; HAITH, D. A.. Water Resource Systems Planning and Analysis. Englewood Cliffs: Prentice-Hall, 1981.

LOPES, J. E. G.; BRAGA, B. P. F.; CONEJO, J. G. L.. Simulação Hidrológica: Aplicações de um modelo simplificado. In: SIMPÓSIO BRASILEIRO DE RECURSOS HÍDRICOS, 4. Anais. Fortaleza: ABRH, 1981. p.42-62.

OLIVEIRA, G. M.; LEITÃO, M. M. V. B. R.; GALVÃO, C. O.; LEITÃO, T. H. V.. Estimativa da Evaporação e Analise de Uso do Coeficiente (kp) do Tanque 'Classe' nas Regiões do Cariri e Sertão da Paraíba. Revista Brasileira de Recursos Hídricos, v.10, n.4, p.73-83, 2005.

RÊGO, J. C.; ALBUQUERQUE, J. P. T.; RIBEIRO, M. M. R.. Uma Análise da Crise de 1998-2000 no Abastecimento D’água de Campina Grande/PB. In: SIMPÓSIO DE RECURSOS HÍDRICOS
DO NORDESTE, 5. Anais. Natal, 2000.

RIMA. Relatório de Impacto Ambiental. Relatório de Impacto sobre o Meio Ambiente do Projeto de integração do rio São Francisco com bacias hidrográficas do nordeste setentrional. Brasília: MIN, 2004.

SANTOS, V. S.; CURI, W. F.; CURI, R. C.; VIEIRA, A. S.. Um Modelo de Otimização Multiobjetivo para Análise de Sistema de Recursos Hídricos I: Metodologia. Revista Brasileira de Recursos Hídricos, v.16, n.4, p.49-60, 2011.

SILVA, W. P.; SILVA, C. M. D. P. S.; CAVALCANTI, C. G. B.; SILVA, D. D. P. S.; SOARES, I. B.; OLIVEIRA, J. A. S.; SILVA, C. D. P. S.. LAB Fit Ajuste de Curvas: Um software em português para tratamento de dados experimentais. Revista Brasileira de Ensino de Física, v.26, n.4, p.419-427, 2004.

SNIS. Sistema Nacional de Informações sobre Saneamento. Série Histórica. Brasília: SNIS, 2018.

TC/BR RIVERSIDE TECHONLOGY. Plano diretor de recursos hídricos da bacia hidrográfica do Rio Paraíba. João Pessoa: SEMARH, 2001.

VIEIRA, V. P. P. B.. Recursos Hídricos e o Desenvolvimento Sustentável do Semiárido Nordestino. Revista Brasileira de Recursos Hídricos, v.1, n.1, p.91-107, 1996.

A CBPC - Companhia Brasileira de Produção Científica (CNPJ: 11.221.422/0001-03) detém os direitos materiais desta publicação. Os direitos referem-se à publicação do trabalho em qualquer parte do mundo, incluindo os direitos às renovações, expansões e disseminações da contribuição, bem como outros direitos subsidiários. Todos os trabalhos publicados eletronicamente poderão posteriormente ser publicados em coletâneas impressas sob coordenação da Sustenere Publishing, da Companhia Brasileira de Produção Científica e seus parceiros autorizados. Os (as) autores (as) preservam os direitos autorais, mas não têm permissão para a publicação da contribuição em outro meio, impresso ou digital, em português ou em tradução. 